\title{
Sistem Buka Tutup Saluran Air Otomatis Berbabis Arduino Uno CH340
}

\author{
Dhantel Rhesa Prawe da*1, Dwiyanto ${ }^{2}$, Rulli Komaria Pujiana ${ }^{3}$ \\ ${ }^{1,3}$ Program Studi Sistem Komputer, STMIK AUB, Surakarta, Indonesia \\ ${ }^{2}$ Program Studi Teknik Elektro, Akademi Teknologi AUB, Surakarta, Indonesia \\ e-mail: *11hantel@stmik-aub.ac.id, ${ }^{3}$ rullikp@gmail.com
}

\begin{abstract}
Abstrak
Akuarium sudah dikenal oleh masyarakat umum sebagai tempat untuk memelihara ikan hias. Namun seringkali ikan hias yang dipelihara mudah mati akibat k esalahan dalam cara pengurasan air akuarium. Olehnya penting dibuatkan sistem kontrol untuk mengatur sirkulasi air. Oleh karena itu dibuatlah sebuah skripsi yang berjudul "Sistem Buka Tutup Saluran Air Otomatis pada Akuarium Berbasis Arduino Uno CH340".

Dimana tujuan penelitian ini menciptakan alat pada akuariumyaitu sistem kontrol buka tutup saluran air otomatis agar mempercepat saat mengganti air yang baru tanpa perlu memindahkan ikan hias. Sistem dibuat secara otomatis untuk menguras air dan kemudian mengisi air kembali secara efektif pada akuarium sesuai air yang dibutuhkan. Alat ini terdiri dari sistem saluran air otomatis dibuat dengan menggunakan board development Arduino Uno CH340 dan saat mengatur aliran air pada saat pengurasan kolampengurasan menggunakan pompa air akuarium Al DC, kemudian saat mengisi air menggun akan solenoid valve untuk mengisi air kembali.

Pada hasil pengujian maka valve solenoid akan terbuka untuk memasukkan air ke akuarium. Pada saat itu juga sensor HC-SR04 membaca ketinggian air. Ketika ketinggian air adalah $13 \mathrm{~cm}$, maka sensor HC-SR04 kembali mengirimkan sinyal pada Arduino Uno CH340. Dan arduino memerintahkan solenoid valve untuk berhenti.
\end{abstract}

Kata kunci-Arduino Uno CH340, Akuarium, Solenoid Valve, Sensor HC-SRO.

\begin{abstract}
The aquarium is known by the general public as a place for raising ornamental fish. But often ornamental fish are susceptible to death because of errors in the aquarium water filtration system. This is a really important way for a control system to regulate water circulation. And so a was made, called The Pre-Automated Water-Duct System on Arduino Arduino CH340. Where the purpose of this research was to create this aquarium apparatus, the control system, unlocks automated sewer caps, to accelerate when replacing fresh water, without remove ornamental fish. Systems were made automatically to drain water and then replenish water effectively in the aquarium as needed water. And this device is an auto mated drainage system made using a board development arduino uno CH340 And when regulating the flow of water at the filling of the pools using an A1 DC aquatic pump, then when filling the water with a solenoid valve to replenish the water. At the test result then the valve solenoid will be open to get water in the aquarium. At this very moment, sensors HC-SRO4 read the water level. When water level is 13 centimeters, the HC-SR04 sensor is re-emitting signal to arduino uno CH340. And arduino ordered the solenoid valve to stop.
\end{abstract}

Keywords-Arduino Uno Ch340, Aquarium, Solenoid Valve, HC-SR04 Sensor.

Received April 3, 2020; Revised April 13, 2020; Accepted December 17, 2020 


\section{PENDAHULUAN}

Kehadiran ikan hias di dalam rumah dapat memberikan berbagai manfaat bagi manusia yaitu turut memberikan nuansa damai, rileks, dan menyenangkan. Aktivitas manusia yang begitu padat bahkan seringkali dilanda stres akibat terpaan berbagai macam urusan dapat terurai dengan melihat gerak-gerik ikan di dalam akuarium atau kolam. Beberapa orang yang tertarik untuk memelihara ikan hias, namun seringkali malas karena ikan hias yang dipelihara dalam akuarium atau kolam mudah mati. Ikan hias di dalam akuarium atau kolam tidak akan mati tanpa sebab. Salah satu penyebab ikan mati adalah kesalahan dalam cara pemeliharaannya.

Proses penggantian air juga berpengruh pada saat mengganti air, ikan harus dipindahkan ke wadah lain, sampai proses pengisian air kembali. Setelah selesai penggantian air, ikan dipindakan lagi ke akuarium. Oleh karena itu banyak ikan yang mati karena stress pada saat perpindahan wadah.

Berdasarkan penjelasan di atas, diperlukan adanya sistem kontrol buka tutup saluran air otomatis agar mempermudah saat mengganti air tanpa perlu memindahkan ikan hias. Sistem dibuat secara otomatis untuk menguras air dan kemudian mengisi air kembali secara efektif pada akuarium sesuai kebutuhan. Sistem saluran air otomatis dibuat dengan menggunakan board development Arduino Uno CH340, sedangkan untuk mengatur aliran air pada saat pengurasan kolam digunakan pompa air DC, kemudian saat mengisi air menggunakan solenoid valve.

\section{METODE PENELITIAN}

Metodologi yang digunakan dalam penelitian ini dimulai dari studi literatur. Sumber studi literatur berupa buku, jurnal ilmiah, serta berbagai sumber internet yang berkaitan dengan penelitian yang akan dilakukan. Kemudian dilakukan analisa terhadap kebutuhan sistem, baik itu perangkat keras maupun perangkat lunak. Dari hasil analisa tersebut, dilakukan proses perancangan sistem.

Tahap selanjutnya adalah implementasi berdasarkan perancangan. Lalu dilakukan pengintegrasian, dimana dilakukan penggabungan sistem perangkat keras maupun perangkat lunak. Kemudian dilakukan pengujian terhadap sistem yang sudah direalisasikan dalam bentuk nyata. Pengujian dilakukan untuk mengetahui apakah sistem yang dirancang sudah sesuai dengan harapan. Hasil dari pengujian selanjutnya akan dianalisis.

\subsection{Wawancara}

Salah satu metode pengumpulan data adalah dengan jalan wawancara, yaitu mendapatkan informasi dengan cara bertanya langsung kepada Arif selaku pemelihara ikan hias di akuarium di tengah jadwal kegiatan sehari-hari mereka. Hasil dari wawancara tersebut dapat disimpulkan bahwa kegiatan pemeliharaan ikan hias pada saat penggantian air harus memindahkan ikan hias dari akuarium ke wadah lain sehingga membuat ikan mudah stress. Dengan demikian dapat menetukan solusi yang tepat atas permasalahan yang ada.

\subsection{Observasi}

Observasi dan mengumpulkan data dengan mengamati secara langsung tentang proses pada saat penggantian air mulai dari pompa air, valve solenoid, dan sensor ketinggian, serta masalah yang akan ditimbulkan dari kondisi atau sistem yang sedang berjalan.

\subsection{Studi Pustaka}

Cara yang dipakai untuk menghimpun data-data atau sumber-sumber yang berhubungan dengan topik yang diangkat dalam penelitian. Yaitu dengan membaca buku-buku literatur, buku skripsi "Sistem akuarium otomatis", materi kuliah maupun sumber lainnya seperti buku pemeliharaan ikan hias, buku-buku lainnya yang berhubungan dengan masalah yang dibahas dan artikel-artikel yang didapat dari internet serta jurnal untuk memperkuat data-data dan masalah yang dihadapi. 


\section{HASIL DAN PEMBAHASAN}

\subsection{Perancangan Alat dan Sistem}

Perancangan alat ini dibagi menjadi tiga tahap, yaitu perancangan mekanik, perancangan elektronik, dan prinsip kerja program.

\subsubsection{Perancangan Sistem Mekanik}

Perancangan sistem mekanik dilakukan dengan menyiapkan wadah yang nantinya digunakan untuk membuat kolam ikan. Pada wadah Gambar 1, dilubangi bagian samping dan belakang untuk keluar masuknya air.

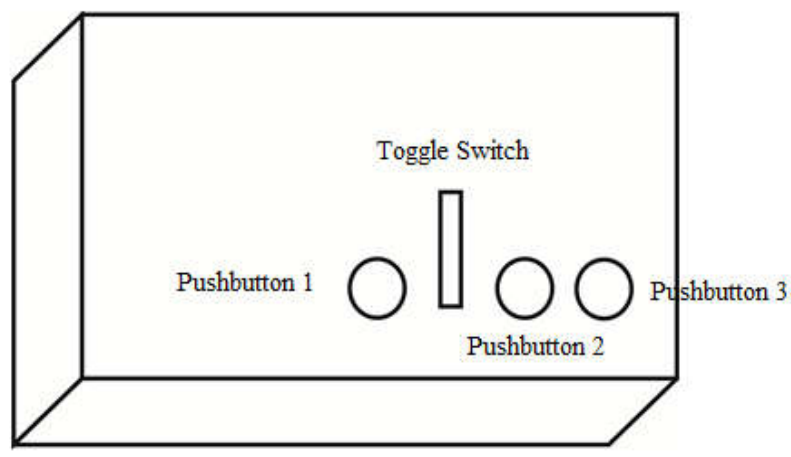

Gambar 1. Rancang Bangun Black Box

Black box digunakan sebagai chasing alat yang telah dibuat (rangkaian Arduino), yang berukuran panjang $18 \mathrm{~cm}$, lebar $11 \mathrm{~cm}$ dan tinggi $6 \mathrm{~cm}$ seperti Gambar 2 .

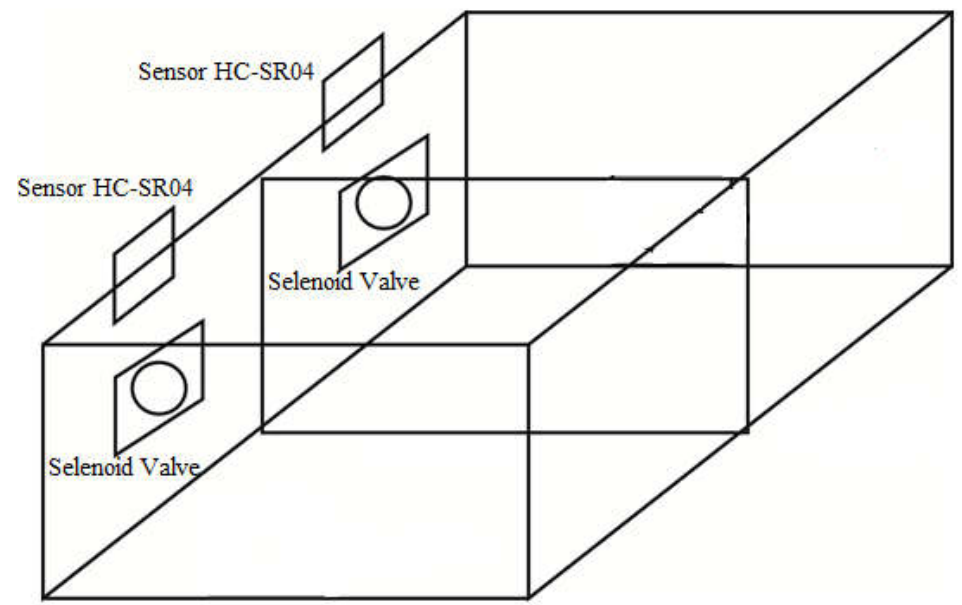

Gambar 2. Rancang Bangun Akuarium

Akuarium yang dirancang memiliki dua buah ruang. Akuarium dibuat dengan menggunakan akrilik bening. Pada masing-masing ruang, terdapat satu lubang yang terletak di belakang sebagai tempat masukknya air setelah air habis. Dengan ukuran akuarium panjang $30 \mathrm{~cm}$, lebar $20 \mathrm{~cm}$, dan tinggi $17 \mathrm{~cm}$.

\subsubsection{Perancangan Sistem Elektronik}

Sistem elektronik yang dirancang pada alat ini memiliki tiga bagian pokok yaitu rangkaian kontrol, rangkaian sensor dan rangkaian Keseluruhan.

\subsubsection{Rangkaian Kontrol}




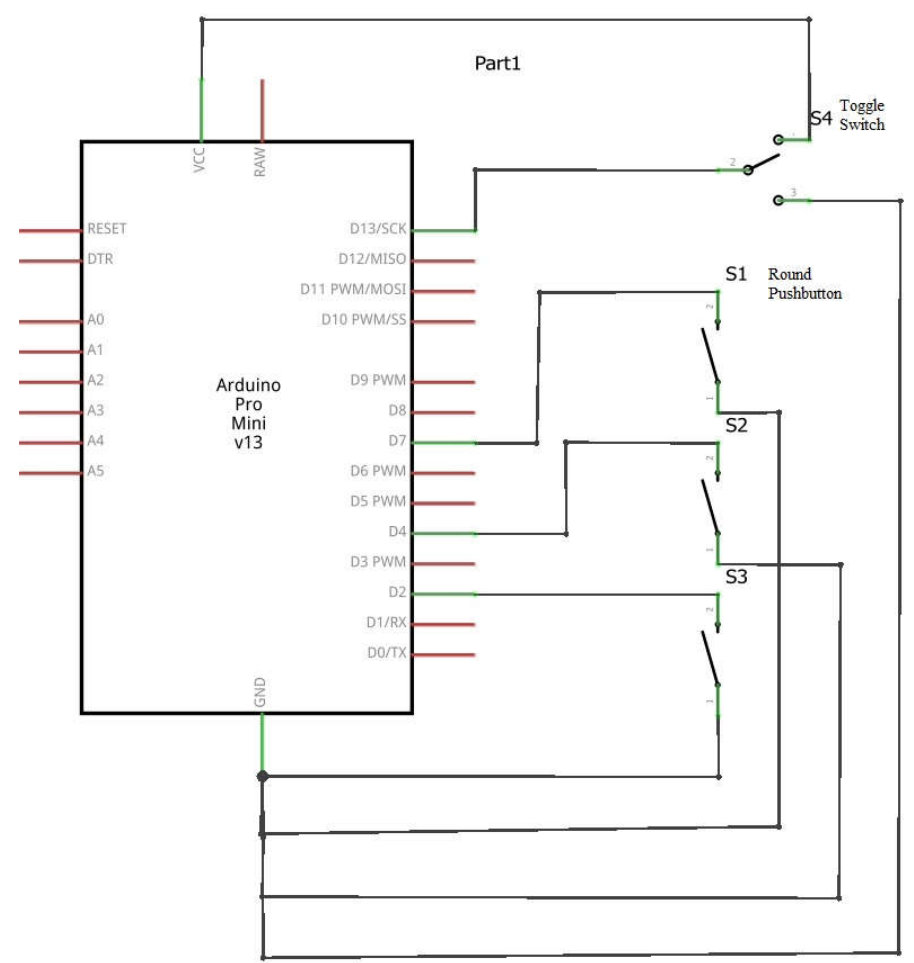

Gambar 3. Rangkaian Input Kontroller

Terlihat pada rangkaian Gambar 3, terdapat tiga buah tombol push button serta satu buah toggle switch. Toggle switch ini berfungsi untuk merubah mode alat menjadi otomatis dan manual. Sedangkan ketiga tombol tersebut berfungsi sebagai tombol buka valve atas dan buka valve bawah (untuk kondisi manual) serta eksekusi perintah jalankan mode otomatis, dimana nantinya pada mode otomatis ini akan diperlukan bantuan sensor ultrasonik HC-SR04 untuk mendeteksi ketinggian air.

\subsubsection{Rangkaian Sensor HC-SR04}

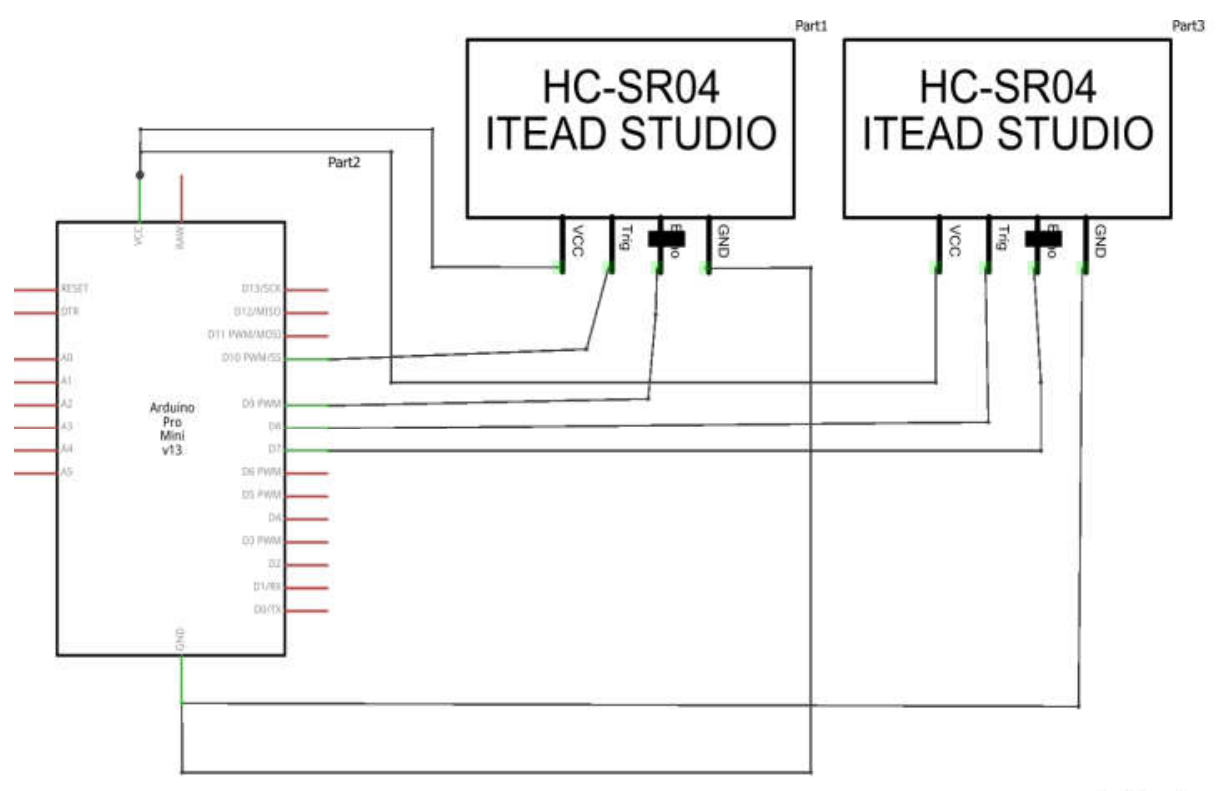

\section{fritzing}

Gambar 4 Rangkaian sensor Ultrasonik HC-SR04

Rangkaian Gambar 4 merupakan rangkaian sensor, pada gambar terlihat ada dua buah sensor untuk masing-masing chamber kolam (terdapat dua ruang kolam). Sensor Ultrasonik 
HC-SR04 memiliki 4 buah kaki, yaitu kaki VCC, kaki trigger, kaki echo, dan kaki ground. Kaki vec sensor ini ditandai dengan kabel warna merah, kaki trigger dan kaki echo ditandai dengan kabel warna kuning, sedangkan kaki ground ditandai dengan kabel warna hitam.

Echo dan trigger dari masing-masing sensor dimasukkan ke pin 8, 9, 10, dan 11 Arduino. Sedangkan VCC masuk ke 5V dan ground dari sensor ini masuk ke ground Arduino dimana terdapat ground universal. Sensor ini memiliki prinsip dimana trigger dari sensor mengeluarkan sebuah suara dengan frekuensi tertentu, suara tersebut akan memantul dan kembali lagi ke sensor dan ditangkap oleh echo. Perbedaan antara suara yang dikeluarkan dan suara yang ditangkap ini nantinya akan dirubah menjadi bentuk jarak.

\subsection{Perancangan Komponen Keseluruhan}

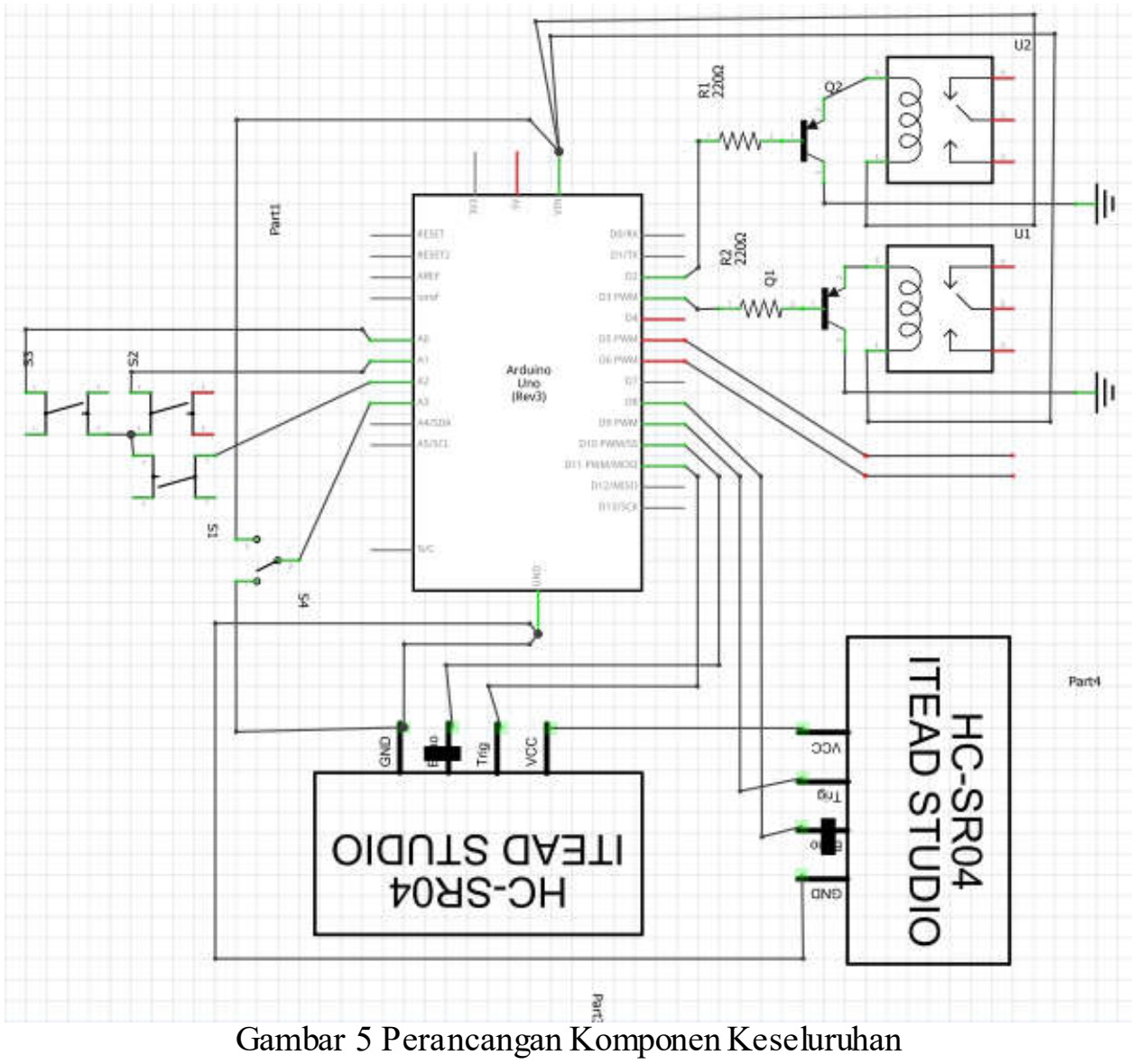

Gambar 5 menunjukan gambar perancangan komponen secara keseluruhan dimana didalam rangkaian telah terdapat arduino uno R3, sensor HC-SR04, toggle switch, push button, pompa air DC.

\subsection{Diagram Prinsip Kerja Alat}

Secara keseluruhann, prinsip kerja alat yang dirancang seperti Gambar 6 sebagai berikut. 


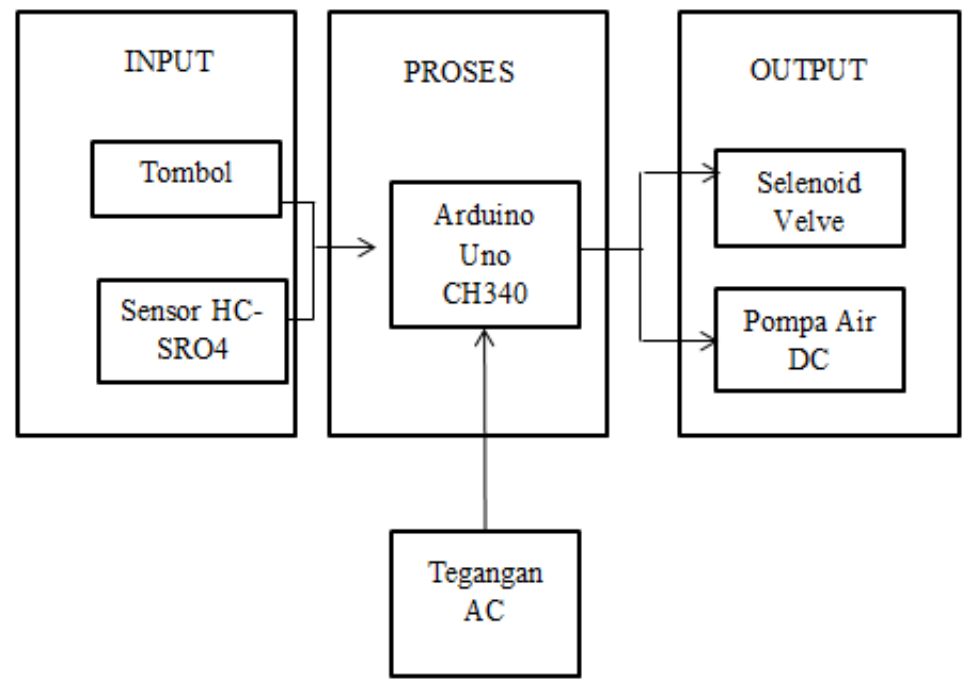

Gambar 6. Diagram Blok Prinsip Kerja Alat

Alat yang dirancang mendapatkan tenganan AC dan dirubah menjadi DC dengan menggunakan adaptor. Alat ini memiliki input 3 tombol dan 1 buah toogle switch agar dapat diganti mode oleh pengguna, yaitu mode otomatis dan mode manual. Serta menggunakan sensor HC-SR04 sebagai input sensor untuk membaca ketinggian air. Lalu semua data pada input dibaca oleh Arduino Uno CH340 dan diteruskan ke output.

\subsection{Pembahasan}

Pengujian sistem mekanik dilakukan dengan memberikan air pada akuarium dan mencari kebocoran pada alat tersebut.

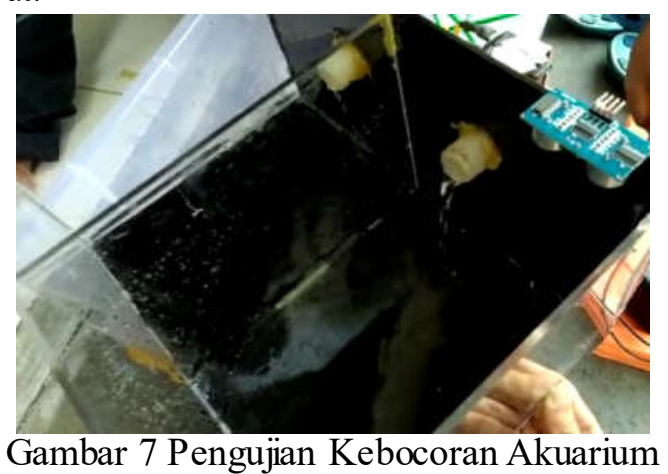

Pengujian selanjutnya yang dilakukan adalah pengujian elektronik dimana masingmasing dari komponen yang digunakan diuji tegangannya. Pengujian ini bertujuan untuk mengetahui nilai tegangan yang dibutuhkan pada masing-masing komponen serta mengetahui noise pada rangkaian. Hasil pengujian tegangan pada rangkaian ditujukan pada Tabel 1.

Tabel 1 Hasil Pengujian Tegangan Rangkaian

\begin{tabular}{|l|l|l|}
\hline No & Nama Komponen & Tegangan (volt) \\
\hline 1 & Arduino Uno & 4,88 \\
\hline 2 & Adaptor DC & 12 \\
\hline 3 & Sensor US HC-SR04 & 4,98 \\
\hline 4 & Relay ON & 12 \\
\hline 5 & Relay OFF & 0 \\
\hline 6 & Transistor & 5 \\
\hline 7 & Solenoid Valve (Tegangan AC) & 220 \\
\hline
\end{tabular}


Berikutnya adalah pengujian sistem minimum berfungsi untuk mengetahui keberhasilan alat yang dirancang dalam melakukan fungsi-fungsinya, seperti:

1. Pengujian sensor

2. Pengujian saklar toogle

3. Pengujian push button

4. Pengujian solenoid valve

Pengujian ini dilakukan dengan memasukkan input dan membuka serial monitor pada arduino. Pada serial monitor arduino akan diketahui nilai jarak dari sensor jarak dimana jarak diukur secara real dan dibandingkan dengan nilai yang muncul pada serial monitor.

Tabel 2 Hasil pengukuran dari sensor jarak.

\begin{tabular}{|c|c|c|}
\hline No & Pengujian re al (cm) & Pengukuran sensor (cm) \\
\hline 1 & 4 & 3 \\
\hline 2 & 5 & 5 \\
\hline 3 & 7 & 6 \\
\hline 4 & 8 & 6 \\
\hline 5 & 9 & 9 \\
\hline 6 & 10 & 9 \\
\hline 7 & 11 & 10 \\
\hline 8 & 12 & 11 \\
\hline 9 & 13 & 13 \\
\hline 10 & 15 & 15 \\
\hline
\end{tabular}

Saat pengujian dapat terjadi noise, dari pengujian antara lima kali terdapat satu kali noise. Noise adalah sinyal-sinyal yang tidak diinginkan yang selalu ada dalam suatu sistem transmisi. Noise ini akan mengganggu kualitas dari sinyal terima yang dïnginkan dan akhirnya menggangu proses penerimaan dan pengiriman data.

Pengujian selanjutnya adalah menguji input yang berupa tiga buah push button dan sebuah toogle switch. Pada pengujian ini dilakukan pemencetan tombol dan melihat data yang dihasilkan pada serial monitor Arduino Uno. Pada pengujian ini dihasilkan data seperti pada Tabel 3.

Tabel 3 Hasil dari Push button input

\begin{tabular}{|l|l|l|}
\hline No & \multicolumn{1}{|c|}{ Kondisi } & \multicolumn{1}{|c|}{ Hasil } \\
\hline 1 & Button 1 ditekan & LOW \\
\hline 2 & Button 2 ditekan & LOW \\
\hline 3 & Button 3 ditekan & LOW \\
\hline 4 & Button 1 tidak ditekan & HIGH \\
\hline 5 & Button 1 tidak ditekan & HIGH \\
\hline 6 & Button 3 tidak ditekan & HIGH \\
\hline 7 & Toggle Switch kearah kanan & HIGH \\
\hline 8 & Toggle Switch kearah kiri & LOW \\
\hline
\end{tabular}

Pengujian solenoid dilakukan dengan membaca nilai yang dihasilkan oleh relay. 
Pengujian terakhir adalah pengujian keseluruhan sistem. Setelah masing-masing dari sistem dan komponen diuji maka dilakukan pengujian secara keseluruhan. Pengujian ini terdiri dari pengujian secara manual dan pengujian secara otomatis seperti Gambar 8.

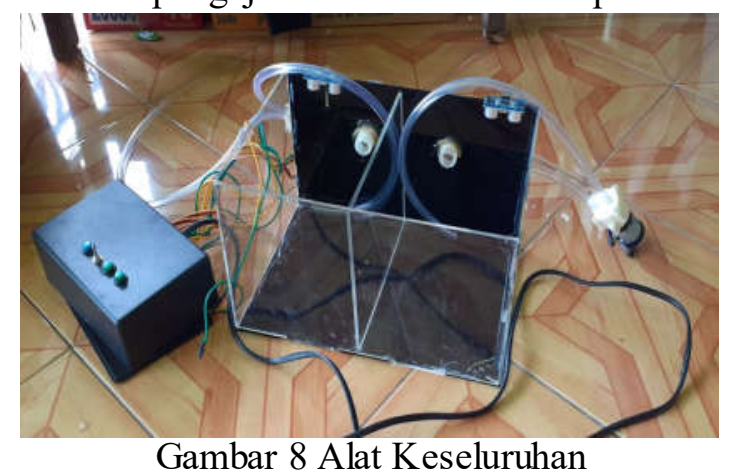

Dari implementasi pengujian alat dan cara penggunaan alat ini terbukti bahwa alat telah dapat digunakan dengan cara yang sudah di tentukan serta alat dapat berjalan sesuai dengan perancangan yang telah dilakukan. Dalam proses penggunaan alat ini memiliki prinsip kerja yaitu :

1. Alat menggunakan Arduino Uno CH340 sebagai main proseseor nya. Pada alat ini terdapat tiga buah tombol dan satu buah toogle switch. Saklar toogle ini berfungsi untuk mengganti mode dari alat yang dirancang, terdapat dua mode yaitu otomatis dan manual. Pada mode otomatis, alat dapat menguras air pada aquarium sendiri tanpa bantuan user. Pada mode manual, user harus melakukan usaha untuk menguras air pada akuarium. Prinsip pengurasan air pada aquarium ini terjadi dengan cara mengeluarkan air pada air aquarium dan memasukkan air dengan menggunakan valve solenoid yang dikontrol dengan menggunakan Arduino Uno CH340.

2. Pada alat ini juga menggunakan sensor ultrasonik seri HC-SR04, sensor ini berfungsi untuk membaca ketinggian pada alat. Sensor ini hanya akan berfungsi pada mode otomatis, pada mode otomatis, ketika tombol pengurasan ditekan, maka pompa air keluar akan aktif dan mengeluarkan air pada aquarium, pada saat itu juga sensor ultrasonik bekerja membaca ketinggian pada aquarium. Ketika ketinggian air pada akuarium menacapai $3 \mathrm{~cm}$, sensor ultranosik mengirimkan sinyal pada Arduino Uno CH340 dan Arduino Uno CH340 memerintahkan pompa air untuk berhenti mengeluarkan air. Selanjutnya valve solenoid akan terbuka untuk memasukkan air ke akuarium. Pada saat itu juga sensor ultra sonik membaca ketinggian air. Ketika ketinggian air adalah $13 \mathrm{~cm}$, maka sensor ultrasonik kembali mengirimkan sinyal pada Arduino Uno CH340. Dan arduino memerintahkan valve solenoid untuk berhenti.

\section{KESIMPULAN}

Berdasarkan hasil perancangan dan implementasi sistem buka tutup saluran air pada akuarium dengan menggunakan board development Arduino Uno CH340, proses untuk dapat mengeluarkan air pada aquarium dengan menggunakan pompa air A1 DC dan memasukkan air dengan menggunakan solenoid valve yang dikontrol dengan menggunakan Arduino Uno $\mathrm{CH} 340$.

Sistem kontrol buka tutup saluran air otomatis yang dibuat dapat mempermudah pengguna saat mengganti air yang baru tanpa perlu memindahkan ikan hias. Sistem dibuat secara otomatis untuk menguras air dan kemudian mengisi air kembali secara efektif pada akuarium sesuai air yang dibutuhkan.

Dapat memilih mode alat, otomatis atau manual dengan menggunakan saklar toogle. Apabila memilih otomatis, saklar toggle diarahkan ke kiri dengan tombol warna biru. Apabila saklar toogle diarahkan kekanan, maka alat akan berubah ke mode manual. 
Terdapat sensor ultrasonic seri HC-SR04, sensor ini berfungsi untuk membaca ketinggian air pada akuarium. Sensor ini hanya akan berfungsi pada mode otomatis, jarak maksimal deteksi air $3 \mathrm{~cm}$ sampai $13 \mathrm{~cm}$.

\section{SARAN}

Saluran air otomatis pada akuarium jauh dari dari kesempurnaan dan untuk memberikan kesempurnaan maka perlu adanya pengembangan lebih lanjut, antara lain :

1. Untuk pengembangan lebih lanjut, dapat digunakan jenis mikrokontroler lain untuk pembuatan saluran air otomatis pada akuarium dengan spesifikasi yang lebih cangggih dan menambah jenis sensor kekeruhan air.

2. Menambahkan sistem pergantian air otomatis pada akuarium secara bergantian dari kolam satu dengan kolam yang lain pada waktu bersamaan.

3. Untuk lebih efisien, dapat menggunakan sensor jenis lain agar lebih aman jika terkena air.

\section{DAFTAR PUSTAKA}

[1] Abdi, Husnul 2019. Macam-macam Ikan Hias Akuarium yang Populer, Mudah Dipelihara. Diakses pada tanggal 2 November 2019.

[2] Andre. 2018. Tutorial Belajar C Part 1: Pengertian Bahasa Pemrograman C.

[3] Arifin, Jaenal. 2017. Prototipe Pendingin Perangkat Telekomunikasi Sumber Arus Dc Menggunakan Smartphone. ISSN 2579-972X

[4] Djukarna. 2019. Praktikum Membuat Adaptor. Diakses pada April 2019

[5] Fitrayu Ulya, Anida. 2016. Rancang Bangun Alat Pengisian Air Otomatis Berbasis Mikrokontroller AT89S51.

[6] Gumilang Putra, Agung. 2019. Realisasi Sistem Kendali Akuarium Otomatis pada Pemeliharaan Ikan Hias Air Tawar. Universitas Telkom. ISSN : 2355-9365.

[7] Jogiyanto. 2005. Analisis dan Desain Sistem Informasi. Pendekatan Terstruktur Teori dan Praktek Aplikasi Bisnis. Yogyakarta : Andi Offset.

[8] Junaidi. 2018. Project Sistem Kendali Elektronik Berbasis Arduino. Bandar Lampung: Aurora.

[9] Kho, Dickson. 2019. Jenis-jenis Saklar (Switch) dalam Rangkaian Elektronika.

[10] Risal, Muhammad. 2017. Sistem Kontrol Sirkulasi Air dan Pemberian Pakan pada Akurium Ikan Hias. STMIK Handayani Makasar.

[11] Santoso, Hari. 2015. Cara Kerja Sensor Ultrasonik, Rangkain dan Aplikasinya.

[12] Satyani, Darti. 2012. Penggunaan Berbagai Wadah Untuk Pembudidayaan Ikan Hias Air Tawar. Vol. 7

[13] Sulbiyah Kurniasih, Siti. 2016. Rancang Bangun Alat Pengisi Air Otomatis Berbasis Mikrokontroler. ISSN : 2338-493x.

[14] Suprianto. 2015. Pengertian Push Button Switch (Saklar Tombol Tekan). Diakses pada tanggal 30 Oktober 2015

[15] Triady, Rocky. 2105. Prototipe Sistem Keran Air Otomatis Berbasis Sensor Flowmeter Pada Gedung Bertingkat. ISSN 2338-493x

[16] Riska, Aditya. 2016. Mengenal Arduino Software (IDE). Diakses pada tanggal 16 Maret 2016] 